\title{
Detection of Military Underground Structures through the Remote Sensing Investigation of Phenological Cycle of Crops
}

\author{
George Melillos $^{1}{ }^{*}$, Kyriacos Themistocleous ${ }^{1}$, George Papadavid ${ }^{2}$, Diofantos G. Hadjimitsis ${ }^{1}$ \\ ${ }^{1}$ School of Engineering and Technology, Department of Civil Engineering and Geomatics, Cyprus University of Technology, \\ Limassol, Cyprus \\ ${ }^{2}$ Agricultural Research Institute, Nicosia, Cyprus \\ Email: ^gn.melillos@edu.cut.ac.cy
}

How to cite this paper: Melillos, G., Themistocleous, K., Papadavid, G. and Hadjimitsis, D.G. (2018) Detection of Military Underground Structures through the Remote Sensing Investigation of Phenological Cycle of Crops. Advances in Remote Sensing, 7, 235-244.

https://doi.org/10.4236/ars.2018.73016

Received: May 16, 2018

Accepted: September 18, 2018

Published: September 21, 2018

Copyright $(9) 2018$ by authors and Scientific Research Publishing Inc. This work is licensed under the Creative Commons Attribution International License (CC BY 4.0).

http://creativecommons.org/licenses/by/4.0/

\begin{abstract}
This paper aims to explore how field spectroscopy is essential for remote sensing studies for the detection and monitoring of various features such military underground structures in Cyprus. A SVC-HR1024 field spectroradiometer was used and in-band reflectances were determined for medium resolution Landsat-7 ETM satellite sensor, in order to study possible differences of the spectral signature of vegetation throughout the phenological cycle of plant growth. In this study, two test areas were identified, analyzed and modelled: 1) Military Structure Area (MSA) where underground structure exists, and 2) Reference Area (RA) where underground military structure does not exist. The Normalized Difference Vegetation Index (NDVI) was applied to Landsat-7 ETM and Sentinel-2 satellite images in order to identify the presence or absence of underground structures in the study area.
\end{abstract}

\section{Keywords}

UAV, Field Spectroscopy, Military Underground Structures, Landsat

\section{Introduction}

The detection of underground and ground military underground structures using satellite imagery and remote sensing could make a significant contribution to defense and security. The launch of the first multispectral and hyperspectral satellites as well as high-resolution satellites confirms that Earth observation techniques are capable of delivering the most in these areas.

Underground structures such as military structures, military bunkers and 
bases, tunnel networks and archaeological remains can affect their surrounding landscapes in different ways, including changes in thermal inertia [1], localized soil moisture content and drainage rates [2], soil composition and vegetation vigor [3]. Vegetation vigor is often observed on the ground as a crop mark, a spot which can be used to denote the presence of underground structures [4]. Crop marks can be formed both as negative marks above wall foundations and as positive marks above the damper and more nutritious soil of buried pits and ditches [4].

Similar studies have been made in archaeology. For instance, archaeological structures buried beneath the soil (i.e., still un-excavated sites) can be detected through remote sensing images as stressed vegetation (crop marks) which can be used as a proxy for the buried archaeological relics. Crop marks may be formed in areas where vegetation grows over near-surface archaeological remains. These features modify the moisture retention compared to the rest of the crop coverage of an area. Depending on the type of the feature, crop vigor may be enhanced or reduced by buried archaeological features [5].

If vegetation grows above buried ditches or moat, then the crop growth is likely to be enhanced. This is due to the topsoil, which holds more moisture than in the surrounding context (especially during periods of water stress). This contrasting phenomenon can be recorded from a suitable airborne or space borne platform and is referred to as a positive crop mark [6] [7]. However, in cases where there is not enough moisture in the retentive soil and there is lack of available water for evapotranspiration (e.g., vegetation grown above building remains or compacted ground), the marks developed are characterized as negative crop marks which are less common than positive crop marks [8] [9].

However, field spectroscopy for the detection of such crop marks still comprises a difficult endeavor since these marks may not be visible in the images if observed over different time periods or at different spatial/spectral resolutions. Former research such as detecting and imaging of underground installments (e.g., tunnels, bunkers) in a hostile environment poses unique challenges on deployment and remote sensing methods [10]. Despite the technological improvements, both in terms of the sensitivity of the sensors (spectral characteristics) and in terms of spatial resolution of satellite datasets, new methods and algorithms are essential to improve Earth observation remote sensing technologies for supporting military research [11]. Field spectroscopy is found to be widely used indeed for several purposes for the detection underground structures such as archeological remains [7].

The most widely used methodology in field spectroscopy concerns in-situ measurements of the electromagnetic radiation of composite surfaces [12]. Spectral data are increasingly incorporated into process-based models of the Earth's surface and the atmosphere. Therefore, it is necessary to acquire data from terrain surfaces, both for providing data for modeling specific parameters and for assisting in scaling-up data from the leaf scale to that of the pixel [13]. The positioning of spectroradiometric reflectance values acquired in-situ through 
field campaigns to match the spectral bands of other satellite sensors such as Landsat- 5 TM has been used for other purposes in the past with a great success [14] [15] [16]. Indeed, field spectroscopy can assist the identification of the suitable spectral region, the suitable vegetation index as well the direct comparison between field and satellite reflectance values for validation and calibration purposes [17] [18].

This paper aims to study underground military structures over vegetated areas using both ground and satellite remote sensing data. Several ground measurements have been carried out in military controlled areas (which are not accessible) throughout the phenological cycle of plant growth. Using a SVC-HR1024 field spectroradiometer, spectroradiometric measurements were collected and analyzed to identify underground military structures using the spectral profile of the vegetated surface over the underground target and the surrounding area for in situ observations. Satellite images from Landsat-7 ETM and Sentinel-2 were used after being scaled with RSR filters. The methodology described in this study can be used to provide useful data to the governmental or local authorities for security purposes. However, the issue of detecting military underground structures remains a difficult issue due the inherent characteristics of such structures. As well, there is a lack of research regarding using vegetation phenology to identify military underground and ground structures.

\section{Resources and Methodology}

\subsection{Study Area}

The methodology has been applied in Cyprus in a defined area of interest. The study area is located within a fenced military area.

Figure 1 shows a military storage bunker similar to what is targeted in the study. The horizontal dimensions of the underground structure are $13 \mathrm{~m} \times 5 \mathrm{~m}$ which is a concrete storage bunker located approximately 2 meters below the ground surface. In order to be able to identify the military structure using remote sensing and Earth observation, it was necessary to also have a baseline area of interest for comparison purposes. Therefore, the Military Structure Area

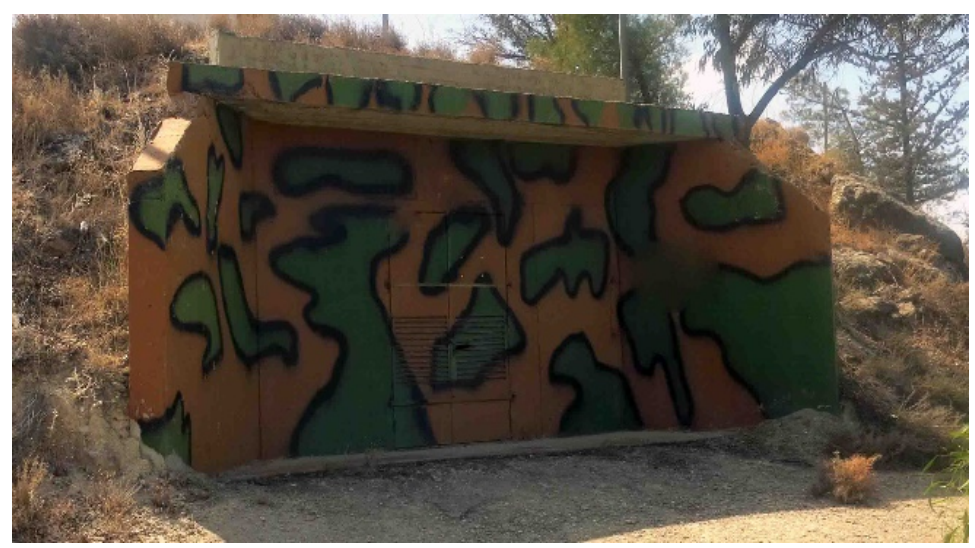

Figure 1. A military storage bunker. 
(MSA) refers where underground structure exists and the Reference Area (RA) refers where underground military structure does not exist.

\subsection{Resources}

The data were collected using the SVC HR-1024 field spectroradiometer which has a spectral range of $350-2500 \mathrm{~nm}$. The measurements were taken between 11:00 am and 13:00 pm (Local Time). A reference calibrated spectral on panel (with reflectance $\approx 100 \%$ ) measurement was used as a reference one, while the measurement over the crops as a target [19].

\subsection{Methodology}

The area of interest was determined first by identifying plots of land with a high probability of military underground structures. Within this area, which included both MRA and RA sites, barley was cultivated and its phenological cycle was measured with in-situ measurements throughout the phenological cycle of plant growth. The phenological cycle is defined as a series of stages or phases in the seasonal cycle of a plant that can be defined by start and end points.

A SVC-1024 spectroradiometer was used to measure reflectance values in order to record the spectral signatures of the study areas. Measurements were taken in a grid format with interval space of $1 \mathrm{~m}$ in the area of interest and random targets were collected each time to compile a representative sample that is statistically reliable. The measurements were taken over the two test areas: the Military Structure Area (MSA) where underground structure exists and the Reference Area (RA) where underground military structure does not exist. In order to study possible differences of the spectral signature of vegetation, as a result of the existence of underground structures. Spectroradiometric measurements were systematically acquired when has been cultivated and covered with vegetation (barley) over the different phases of the phenological cycle of barley crops. Figure 2 shows the area of interest during the construction of test field, the cultivation of barley crops and the phenological cycle of the crop growing in the region.
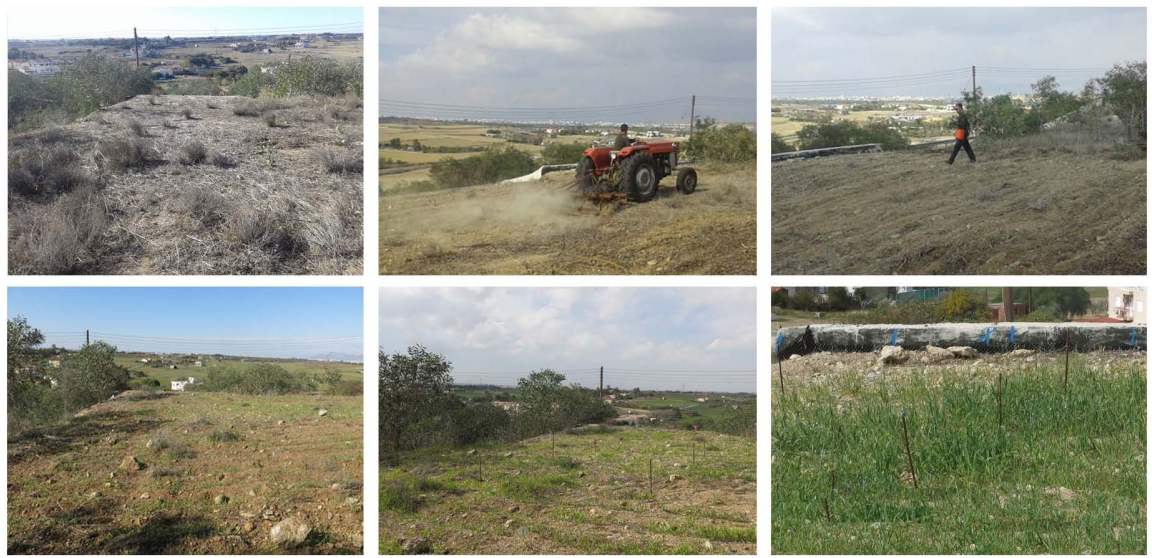

Figure 2. The test field in Study area during its construction, cultivation and barley growth. 
The overall methodology adopted in this study consists of four steps briefly described below (see Figure 3):

- Step 1: The area of interest containing an underground structure was selected as a test area.

- Step 2: Spectroradiometric measurements were taken over the MSA in order to collect spectral signatures.

- Step 3: Spectroradiometric measurements were taken over the RA in order to collect spectral signatures.

- Step 4: In-band analysis using Landsat-7 ETM (and Sentinel-2) after scaling up the narrow band reflectance measurements based on Landsat-7ETM (and Sentinel-2) relative spectral response (RSR) filters.

- Step 5: Evaluation of spectral signatures.

- Step 6: Results and comparison using Landsat-7 ETM and Sentinel-2 satellite images to identify underground structures.

\section{Results and Discussion}

A comparison of the two study areas using band 1, band 2, band 3 and band 4 of the Landsat-7 ETM was conducted.

\section{Military Structure Area (MSA) and Reference Area (RA)}

The two areas MSA and RA have been compared using satellite images and

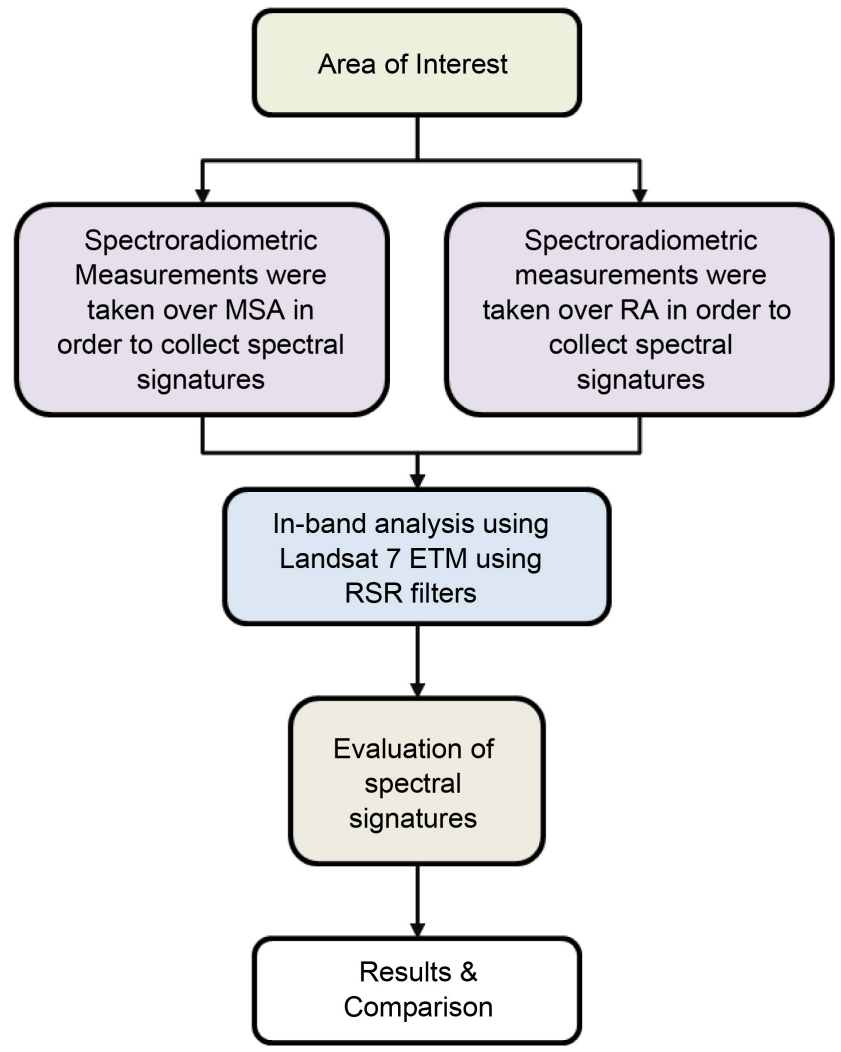

Figure 3. The steps of the methodology adopted. 
in-situ measurements. Using RSR filters for the bands, the reflectance response of each different type of vegetation and soil for the satellite sensor (Landsat-7 ETM) is measured.

Figure 4 and Figure 5 show the "Average" values for mean reflectance spectra for Band 1, Band 2, Band 3 and Band 4 for each phenological stage respectively for the two areas. Significant differences were observed between areas the MSA and RA, due the presence and absence of a military underground structure, respectively. More specifically, in the RA, the reflectance response is higher during the

\section{MSA}

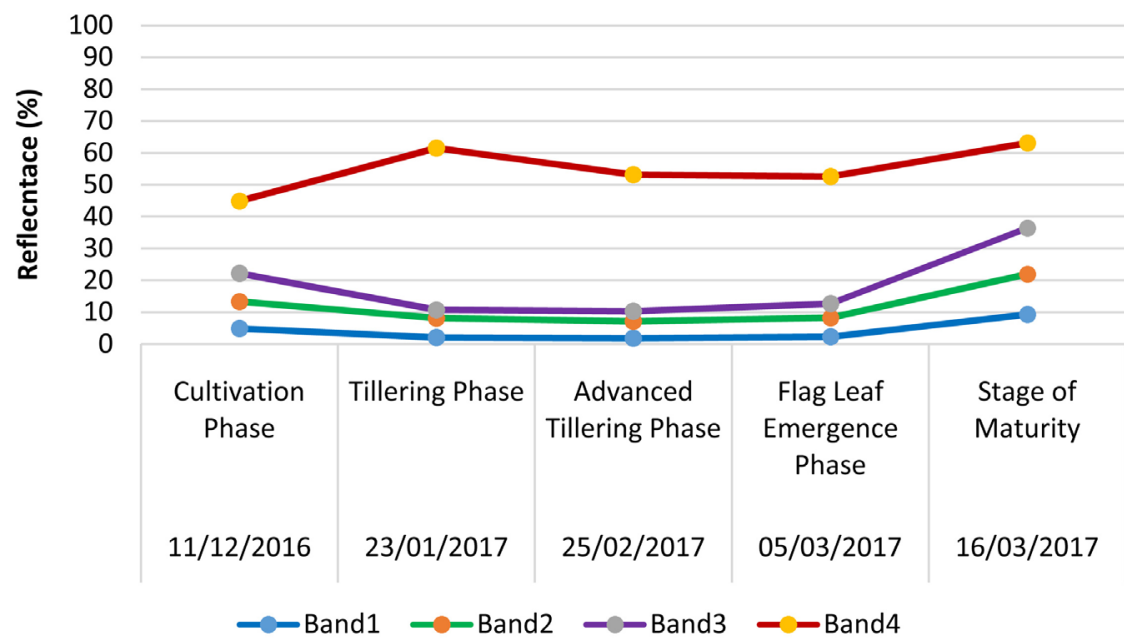

Figure 4. Band 1, Band 2, Band 3 and Band 4 average values for mean reflectance spectra throughout phenological cycle for MSA.

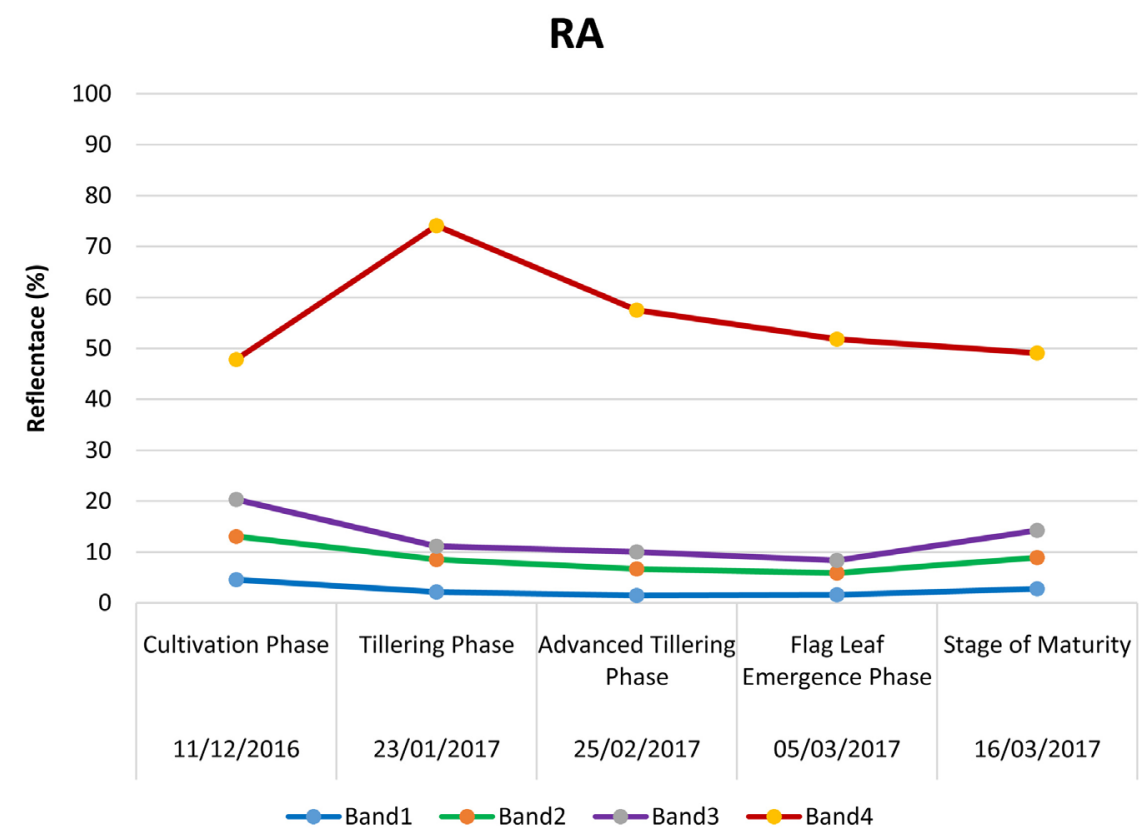

Figure 5. Band 1, Band 2, Band 3 and Band 4 average values for mean reflectance spectra throughout phenological cycle for RA. 
"Tillering Phase". However, during the Maturity phase of in the target area MSA, the reflectance response is higher than RA. This occurs due the presence and non-presence of underground structure. Furthermore, substantial differences were observed between areas MSA and RA during advanced "Tillering Phase".

Satellite images of the MRA were derived from Landsat-7 for the months of January to March, 2017. The Normalized Difference Vegetation Index (NDVI) was applied to the images throughout the duration of field measurements.

The NDVI normalizes green leaf scattering in the near-infrared wavelength (NIR) and chlorophyll absorption in the red wavelength (RED) can be described as

$$
\mathrm{NDVI}=(\rho \mathrm{NIR}-\rho \mathrm{RED}) /(\rho \mathrm{NIR}+\rho \mathrm{RED})
$$

Where $\rho \mathrm{NIR}$ and $\rho \mathrm{RED}$ are the atmospherically or partially atmospherically corrected surface reflectance values of the near-infrared of red wavelengths [20].

The range of NDVI values is from -1 to 1 ; generally, healthy vegetation NDVI ranges between 0.20 and 0.80 . As is evident in Figure 6, the increase in vegetation makes the MRA more pronounced and easier to identify, as is indicated in the satellite image from March 7 2017, which have been circled in red.

Following, Sentinel-2 satellite images of the MRA were taken between February 2017 and June, 2017. NDVI was applied to the Sentinel-2 images throughout the duration of field measurements. The MRA is indicated by the dotted circle in Figure 7. As is evident, the underground bunker becomes more evident towards

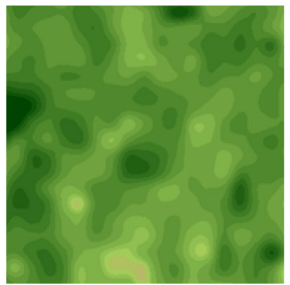

2017-01-18

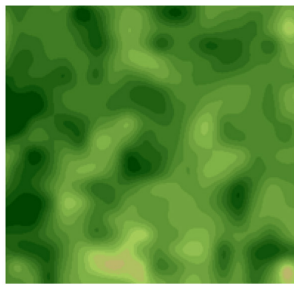

2017-02-03

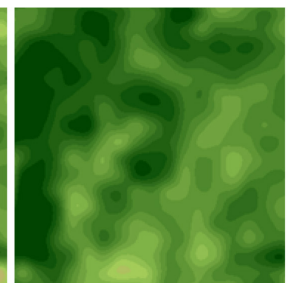

2017-02-19

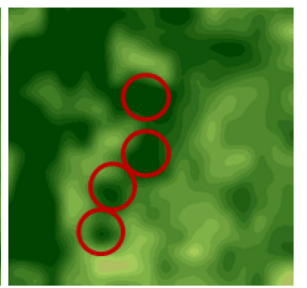

2017-03-07

Figure 6. NDVI applied to Landsat-7 images of MRA from January 2017 to March, 2017.

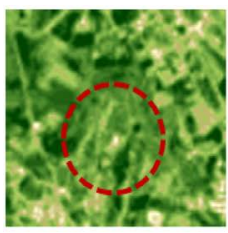

2017-02-03

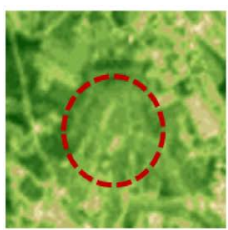

2017-04-04

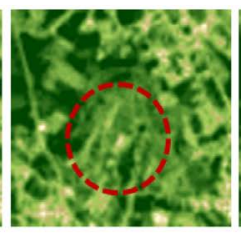

2017-02-13

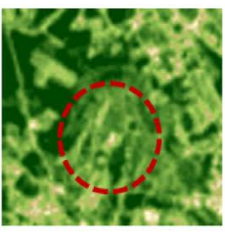

2017-02-23

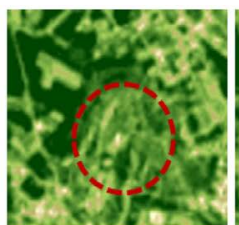

2017-03-05

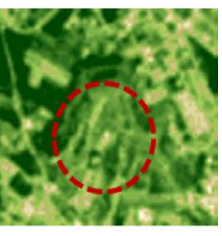

2017-03-25

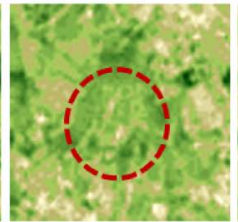

2017-04-24

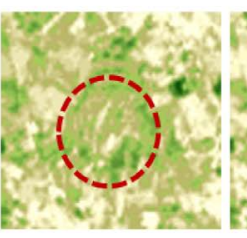

2017-05-04

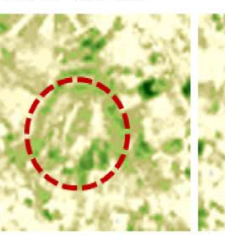

2017-05-24

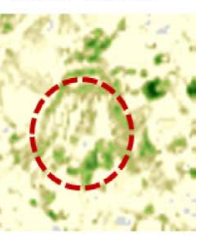

2017-06-13

Figure 7. NDVI applied to Sentinel-2 satellite images from February 2017 to June 2017. 
the end of the phenological cycle of the barley crop.

\section{Conclusions}

In this study, it was demonstrated how remote sensing can be exploited as a monitoring and decision-making tool by an appropriate agency to tackle military and security issues related to the presence of underground military structures. The application of remote sensing in defense and security merges the technological improvements of remote sensing sensors with military needs to improve the quality of information retrieved from remote sensing data.

The study found that Earth observation is a valuable aid in military surveys, especially for monitoring and detecting underground military structures. Surveys are used regularly in military organizations to help leaders make decisions [21]. In this study, field spectroscopy measurements were used to detect underground military structures throughout the phenological cycle of the barley crop. Spectroradiometric measurements can be used as an alternative approach to identify underground military structures, since they can provide accurate spectral signatures for a wide spectral region. Anomalies in the crop spectral signatures resulting from an existing underground structure can be recorded using spectroradiometer.

Indeed, the phenological cycle of vegetation can be used for detecting military underground structures combining with in-band reflectances from medium resolution Landsat-7 ETM satellite sensor and Sentinel-2 sensor. The methodology described in this study supports the detection of military underground structure. Areas covered by natural soil where underground structures are present or absent can easily be detected as a result of the change in the spectral signature of the overlying vegetation. Further testing and field spectroradiometric measurements will be performed to study other types of military underground structures in order to evaluate the above results and the satellites' spectral sensitivity. Spectral signatures of in-situ data, measured with a spectroradiometer, can be used to assess the effectiveness of several available satellite sensors [22]. The development of a standard model/methodology framework to be produced through the phenological stages of crops for locating military underground structures is an innovation in military operations research. Additionally, the rapid collection of Unmanned Aerial Vehicle (UAV) remote sensing images plays an important role [23]. UAV may be used to survey the area with visible and near-infrared cameras to generate NDVI values or any other Vegetation Indices for comparison to the in-situ spectroradiometric measurements. The methodology presented in this study can be further extended to using other satellite sensors, especially to the next new generation high-resolution satellites.

\section{Acknowledgements}

Acknowledgments are given to the Remote Sensing and Geo-Environment Laboratory of the Department of Civil Engineering and Geomatics, at the Cyprus 
University of Technology for its support. This publication is part of G. Melillos $\mathrm{PhD}$ thesis.

\section{Conflicts of Interest}

The authors declare no conflicts of interest regarding the publication of this paper.

\section{References}

[1] Gunn, D.A., Marsh, S.H., Gibson, A., Ager, G.J., McManus, K.B., Caunt, S. and Culshaw, M.G. (2008) Remote Thermal IR Surveying to Detect Abandoned Mineshafts in Former Mining Areas. Quarterly Journal of Engineering Geology \& $\mathrm{Hy}$ drogeology, 41, 357-370. https://doi.org/10.1144/1470-9236/07-204

[2] KMC (2008) Priddy Mineries. A Walk through History.

[3] Milton, E.J. and Rollin, E.M. (2006) Estimating the Irradiance Spectrum from Measurements in a Limited Number of Spectral Bands. Remote Sensing of Environment, 100, 348-355. https://doi.org/10.1016/j.rse.2005.10.016

[4] Hadjimitsis, D.G., Agapiou, A., Themistocleous, K., Alexakis, D.D. and Sarris, A. (2013) Remote Sensing for Archaeological Applications: Management, Documentation and Monitoring. In: Hadjimitsis, D.G., Ed., Remote Sensing of Environment-Integrated Approaches, InTech, 57-95.

[5] Winton, H. and Horne, P. (2010) National Archives for National Survey Programmes: NMP and the English Heritage Aerial Photograph Collection. In: Cowley, D., Standring, R.A. and Abicht, M.J., Eds., Landscapes through the Lens: Aerial Photographs and Historic Environment, Oxbow Books, Oxford, 7-18.

[6] Agapiou, A., Alexakis, D.D. and Hadjimitsis, D.G. (2014) Spectral Sensitivity of ALOS, ASTER, IKONOS, LANDSAT and SPOT Satellite Imagery Intended for the Detection of Archaeological Crop Marks. International Journal of Digital Earth, 7, 351-372. https://doi.org/10.1080/17538947.2012.674159

[7] Agapiou, A., Hadjimitsis, D.G., Alexakis, D.D. and Papadavid, G. (2012) Examining the Phenological Cycle of Barley (Hordeum vulgare) Using Satellite and in Situ Spectroradiometer Measurements for the Detection of Buried Archaeological Remains. GIScience \& Remote Sensing, 49, 854-872.

https://doi.org/10.2747/1548-1603.49.6.854

[8] Lasaponara, R. and Masini, N. (2007) Detection of Archaeological Crop Marks by Using Satellite QuickBird Multispectral Imagery. Journal of Archaeological Science, 34, 214-221. https://doi.org/10.1016/j.jas.2006.04.014

[9] Riley, D.N. (1979) Factors in the Development of Crop Marks. Air Photography and Archaeology, 4, 28-32.

[10] ARO (2009) Detection of Underground Installations in Hostile Environments. http://www.cs.tau.ac.il/ nin/papers/ARORep9Feb10.pdf

[11] Themistocleous, K., Agapiou, A., Cuca, B. and Hadjimitsis, D.G. (2015) Unmanned Aerial Systems and Spectroscopy for Remote Sensing Applications in Archaeology. International Archives of the Photogrammetry, Remote Sensing and Spatial Information Sciences, 40, 1419-1423. https://doi.org/10.5194/isprsarchives-XL-7-W3-1419-2015

[12] Parcak, S.H. (2009) Satellite Remote Sensing for Archaeology. Routledge, Abingdon, 81-104, 109-111, 147-170. 
[13] Shirazi, S.A.J. (2006) Karez Irrigation in Balochistan. http://pakistaniat.com/s006/09/20/karez-balochistan-pakistan-irrigation

[14] Hadjimitsis, D.G. and Clayton, C. (2011) Field Spectroscopy for Assisting Water Quality Monitoring and Assessment in Water Treatment Reservoirs Using Atmospheric Corrected Satellite Remotely Sensed Imagery. Remote Sensing, 3, 362-377. https://doi.org/10.3390/rs3020362

[15] Mettas, C., Agapiou, A., Themistocleous, K., et al. (2016) Risk Provision Using Field Spectroscopy to Identify Spectral Regions for the Detection of Defects in Flexible Pavements. Natural Hazards, 83, 83-96. https://doi.org/10.1007/s11069-016-2262-8

[16] Papoutsa, C., Retalis, A., Toulios, L. and Hadjimitsis, D.G. (2014) Defining the Landsat TM/ETM+ and CHRIS/PROBA Spectral Regions in Which Turbidity Can Be Retrieved in Inland Waterbodies Using Field Spectroscopy. International Journal of Remote Sensing, 35, 1674-1692. https://doi.org/10.1080/01431161.2014.882029

[17] Hadjimitsis, D.G., Papadavid, G., Agapiou, A., Themistocleous, K., Hadjimitsis, M.G., Retalis, A., Michaelides, S., Chrysoulakis, N., Toulios, L. and Clayton, C.R.I. (2010) Atmospheric Correction for Satellite Remotely Sensed Data Intended for Agricultural Applications: Impact on Vegetation Indices. Natural Hazards and Earth System Sciences, 10, 89-95. https://doi.org/10.5194/nhess-10-89-2010

[18] Hadjimitsis, D., Themistocleous, K., Trigkas, V., Matsas, A., Retalis, A. and Chrysoulakis, N. (2010) Spectro-Radiometric Measurements of Non-Variant Targets Intended for the Removal of Atmospheric Effects from Satellite Images: The Case Study of Lemesos Area in Cyprus. Proceedings of SPIE, 7827, 78270D.

[19] Papadavid, G., Hadjimitsis, D.G., Fedra, K. and Michaelides, S. (2011) Estimating Evapotranspiration for Annual Crops in Cyprus Using Remote Sensing. Advances in Geosciences, 30, 31-37. https://doi.org/10.5194/adgeo-30-31-2011

[20] Agapiou, A., Hadjimitsis, D.G. and Alexakis, D.D. (2012) Evaluation of Broadband and Narrowband Vegetation Indices for the Identification of Archaeological Crop Marks. Remote Sensing, 4, 3892-3919. https://doi.org/10.3390/rs4123892

[21] Artino Jr., A.R. (2017) Good Decisions Cannot Be Made from Bad Surveys. Military Medicine, 182, 1464-1465.

[22] Melillos, G., Themistocleous, K., Papadavid, G., Agapiou, A., Michaelides, S., Prodromou, M. and Hadjimitsis, D.G. (2016) Integrated Use of Field Spectroscopy and Satellite Remote Sensing for Defence and Security Applications in Cyprus. Detection and Sensing of Mines, Explosive Objects, and Obscured Targets, Baltimore, 18-21 April 2016, Vol. 9688, 96880F.

[23] Shumin, W., Xiaoqing, W., Aixia, D., Xiaoxiang, Y., Ling, D. and Xiang, D. (2018) Near Real-Time Georeference of Umanned Aerial Vehicle Images for Post-Earthquake Response. International Archives of the Photogrammetry, Remote Sensing \& Spatial Information Sciences, 42, 1773-1776. 